\title{
Electro-oculography in bilateral optic neuropathy
}

\author{
Padmini Dahanayake ${ }^{1,2^{*}}$, Tharaka L. Dassanayake ${ }^{1,2,3}$, Manoji Pathirage ${ }^{2,4}$, Saman Senanayake ${ }^{5}$, Mike Sedgwick \\ and Vajira Weerasinghe $e^{1,2}$
}

\begin{abstract}
Objective: Effect of bilateral, optic neuropathy on the function of retinal pigment epithelium has not been investigated extensively to date. This study aimed to determine the effect of bilateral, optic neuropathy on light peak:dark trough ratio, light peak and dark trough values of electro-oculography. Thirty-seven patients with a clinical diagnosis of bilateral optic neuropathy and 40 control subjects were recruited in this observational, cross-sectional study, carried out at the Neurophysiology unit, Teaching Hospital, Peradeniya, Sri Lanka. Pattern reversal visual evoked potentials, pattern electroretinography and electro-oculography were recorded in all of them.

Results: Twenty-four patients (64.9\%) had reduced light peak:dark trough ratio values. The median light peak:dark trough ratio \pm inter quartile range of the patient group (1.50 \pm 0.4$)$ was significantly lower than that of the controls $(1.80 \pm 0.2),(p<0.001)$. Median dark trough value was significantly higher in patients compared to the control value. These changes may be due to higher conductance of ion channels in the retinal pigment epithelium, sub retinal space creation, changes in choroidal circulation or secondary to photoreceptor abnormalities in the macular region. These results indicate that retinal pigment epithelium might be affected in bilateral optic neuropathy.
\end{abstract}

Keywords: LP:DT ratio, Bilateral, Electro-oculography, Optic neuropathy

\section{Introduction}

Acute demyelinating optic neuropathy is a clinical diagnosis. The history points to the aetiology of the optic neuropathy [1]. Pattern reversal visual evoked potentials (PRVEP) is a highly sensitive test of demyelinating optic nerve damage [2]. The retinal pigment epithelium (RPE) is assumed to be unaffected in optic neuropathy, but has not been studied. Its function can be tested by electro-oculography (EOG) which allows an assessment of the standing potential across the RPE [3]. The ratio of the potential between light and dark adaptation, known as the LP:DT ratio (light peak:dark trough ratio), is an essential diagnostic test in retinal disorders $[4,5]$. A study done in patients with ischemic optic neuropathy showed

\footnotetext{
*Correspondence: padminid@pdn.ac.lk

${ }^{1}$ Department of Physiology, Faculty of Medicine, University of Peradeniya, Peradeniya 20400, Sri Lanka

Full list of author information is available at the end of the article
}

a decrease in the EOG potentials presumably due to ischemia in the RPE [6]. The EOG in other forms of optic neuropathy has not been reported.

Optic neuropathy is commonly associated with multiple sclerosis in patients reported in the Western literature and this is mostly unilateral [7]. Compared to the West, the prevalence of bilateral optic neuropathy is higher in Asians, and the conversion of optic neuropathy into multiple sclerosis is less common [8]. The causation of the higher prevalence of bilateral optic neuropathy in Asia is not known although a post-viral pathology has been implicated [9].

Given the scarcity of evidence of the RPE electrophysiology in optic neuropathy, and higher prevalence of bilateral optic neuropathy in Asia, the aim of this study was to evaluate the effect of bilateral, demyelinating optic neuropathy on the RPE as estimated by the LP:DT ratio, 
amplitudes of light peak (LP) and dark trough (DT) of EOG.

\section{Main text \\ Materials and methods Study setting and participants}

This was a cross-sectional study in which we compared a test group of patients with optic neuropathy and a healthy control group. The study was carried out at the Neurophysiology Unit of the Teaching Hospital, Peradeniya in Sri Lanka between February 2018 to October 2019. The study design and protocols complied with the code of ethics of the World Medical Association Declaration of Helsinki [10].

A sample of 36 subjects per each group was required to observe an effect size of 0.7 , with a $90 \%$ power at $\alpha$-error probability of 0.05 . Thirty seven patients $\geq 18$ years of age with a clinical diagnosis of bilateral optic neuropathy referred by consultant ophthalmologists within 21 days of onset of ocular symptoms were recruited. Patients were diagnosed by the sudden onset of visual impairment, positive relative afferent papillary defect (RAPD) and fundoscopic changes. One of the co authors, who is a specialist ophthalmologist (SS) clinically examined and conducted fundoscopic examination of the potential subjects. None of the recruited subjects had previous eye diseases, evidence of neurological diseases or fundoscopic features of other eye pathologies that might confound our results. The control group comprised 40 healthy subjects of age $\geq 18$ years with normal or corrected-to-normal vision in neuro-ophthalmologic examination. All subjects had a neuro-ophthalmologic assessment which included; measurements of visual acuity, visual field, colour vision, pupillary reflexes, fundoscopy and ocular motor examination at the referring ophthalmology units. Then visual electrophysiological tests viz. PRVEP by Natus machine (USA), pattern electroretinography (PERG) by Nicolet Viking Quest machine (USA) and EOG were performed in each subject conforming to International society for clinical electrophysiology of vision (ISCEV) guidelines [4, $11,12]$.

\section{Assessment of electro-oculography}

The EOG waveforms were recorded using the Natus EMG/NCV/EP machine (USA). Pupils were not dilated as it was shown that application of pupillary dilatation does not influence the quality or the results of electrooculograms [13]. The bitemporal method was used to record EOG waveforms. Silver/silver chloride electrodes were used. The active and reference electrodes were attached to the outer canthi of each eye, thus collecting a compound potential difference resulting from both eyes. The ground electrode was placed at $\mathrm{Cz}$. Band pass filters were set to $0.1 \mathrm{~Hz}$ and $30 \mathrm{~Hz}$. A Ganzfeld dome provided the stimulation. Two fixating lights were located in the Ganzfeld dome, $15^{\circ}$ apart left and right of centre. The patient was kept in stable indoor lighting for at least 30 min before the test. Fixation lights in the Ganzfeld dome were set to alternate at a frequency of once per second, for $10 \mathrm{~s}$ out of every minute. The EOG potentials were recorded for once per second for $10 \mathrm{~s}$ every minute as the eyes moved to left and right according to the alternating lights in the Ganzfeld dome. Auditory cues were used during the recordings. The procedure of making saccades was practiced with the recording system before dark adaptation, to familiarize the patient with the task and to check on the stability and quality of the recorded saccades. The same procedure was used to test the control subjects. EOG recording began with the beginning of the dark adaptation; the EOG potentials being recorded once a minute for $10 \mathrm{~s}$. The dark phase of the EOG potentials lasted for $15 \mathrm{~min}$. Then the room lights and adapting light of Ganzfeld dome were switched on. The adapting light of Ganzfeld dome was a white light with a luminance of $100 \mathrm{cdm}^{-2}$. The light phase recording lasted for another $15 \mathrm{~min}$ [4]. The patient was positioned in the headrest of the Ganzfeld stimulator throughout the procedure, with eyes open to maintain retinal illumination. The EOG amplitudes were measured in microvolts $(\mu \mathrm{V})$ manually after visual inspection. The effects of overshoot or irregular saccades were avoided.

The average of the EOG amplitudes within each $10 \mathrm{~s}$ recording epoch was taken and plotted against time. Then the underlying physiologic curve was drawn using computer-based curve fitting algorithms to derive reliable dark trough (DT) and light peak (LP) amplitudes. Then the LP:DT ratio was calculated by dividing the smoothed light peak by dark trough value for each subject.

\section{Data analysis}

Continuous outcomes measures, i.e. PRVEP latencies, PRVEP amplitudes, PERG latencies, PERG amplitudes, amplitudes of light peak and dark trough, LP:DT ratios showed skewed distributions, and hence are reported as medians and inter quartile ranges (IQR) and were compared between groups using Mann-Whitney U test. The comparisons were interpreted as significant at a cut-off $\mathrm{p}$ value $<0.05$. IBM SPSS statistics for windows, version 22.0. was used to analyze the data and Graph Pad Prism version 5.03 was used to create the graphs.

\section{Results}

\section{Demographic and clinical characteristics}

There were 37 patients with bilateral optic neuropathy (15 (40.5\%) males; median age: $47.0 \pm$ IQR 23 ; range 18-70 years) in the test group and 40 subjects in the 
control group (34.8\% males; median age: $34 \pm \mathrm{IQR} 18$; range 24-60 years). All patients had a clinical history of sudden onset functional visual disturbances, most frequently blurred vision. The median duration to presentation was $10 \pm$ IQR 14 days, with a range of 2-21 days. Fourteen (37.8\%) patients had normal fundoscopy and 23 (62.1\%) showed optic disc edema. Sixteen had magnetic resonance imaging (MRI) and 4 showed features of multiple sclerosis, 12 had a normal MRI. Twenty three (62.1\%) had ocular pain at the onset of the clinical symptoms, but none had pain at the time of the visual electrophysiological examination. RAPD was positive in 24 (64.9\%) patients. Median visual acuity by logarithm of the minimal angle of resolution $(\log M A R)$ units was $+0.50 \pm 0.8$ in the right eye and $+0.20 \pm 0.5$ in the left eye.

\section{Pattern reversal visual evoked potentials}

Median N75, P100 and N145 latencies in both eyes were significantly prolonged in patients with optic neuropathy when compared with the control group (see
Additional file 1: Table S1), signifying demyelinating optic neuropathy.

\section{Pattern electroretinography}

There was no significant difference in median N35, P50 and N95 latencies and amplitudes of both eyes in the patients compared to the control group (see Additional file 1: Table S2). However, 9 patients in right eye and 11 patients in left eye had delayed P50 latency values, whereas 4 patients in right eye and 5 patients in left eye had absent P50 peak. N95 peak was absent in 7 patients in each eye, whereas 3 patients in right eye and 5 patients in left eye had delayed N95 latencies.

\section{Electro-oculography}

Absolute EOG amplitude values plotted over $30 \mathrm{~min}$, smoothed interpolation curves, and the light peaks and dark troughs are shown in Fig. 1. The median LP:DT ratio \pm IQR of the patient group $(1.50 \pm 0.4)$ was significantly lower than that of the controls (1.80 \pm 0.2$)$ (Fig. 2). Twenty-four (64.9\%) patients had an LP:DT ratio below

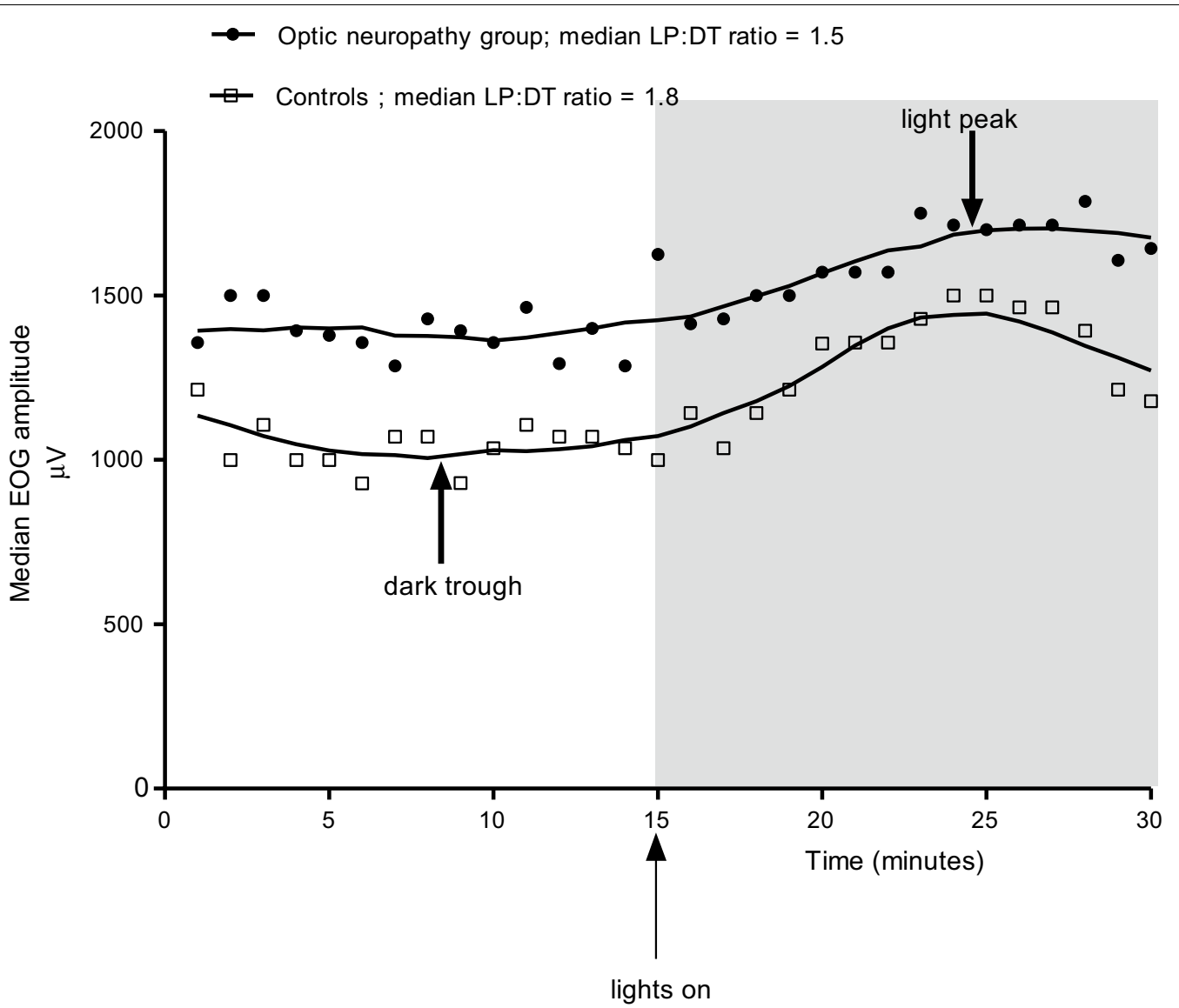

Fig. 1 Median EOG waveforms in dark and light phases over 30 min in optic neuropathy group and the controls (LP:DT ratio= light peak:dark trough ratio) 


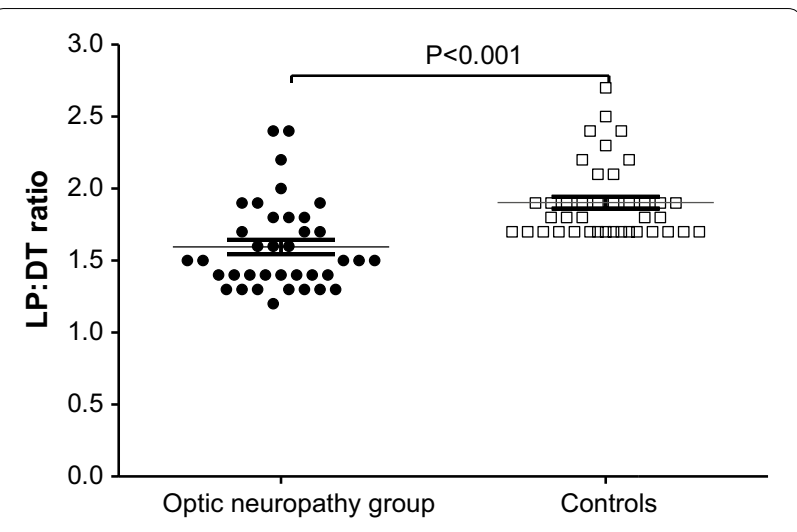

Fig. 2 LP:DT ratio values between optic neuropathy group and the controls (LP:DT ratio = light peak:dark trough ratio)

Table 1 EOG parameters between optic neuropathy group and controls

\begin{tabular}{llcr}
\hline EOG parameter & $\begin{array}{l}\text { Optic neuropathy } \\
\text { group }(\mathbf{n}=\mathbf{3 7}) \\
\text { Median } \pm \text { IQR }\end{array}$ & $\begin{array}{l}\text { Controls }(\mathbf{n}=40) \\
\text { Median } \pm \text { IQR }\end{array}$ & p value \\
\hline Light peak $(\mu \mathrm{V})$ & $1860(984.3)$ & $1700.6(718.9)$ & 0.16 \\
Dark trough $(\mu \mathrm{V})$ & $1140(640)$ & $860(482.5)$ & $* 0.001$ \\
LP:DT ratio & $1.50(0.4)$ & $1.80(0.2)$ & $*<0.001$ \\
\hline
\end{tabular}

IQR inter quartile range

1.7, which is the ISCEV, cut off lower limit of the normal range and the lowest LP:DT ratio observed in the control group [14]. Median dark trough amplitude of the patient group was significantly larger than that of the controls (Fig. 1, Table 1).

\section{Discussion}

In the present study, nearly two-thirds (64.9\%) of the optic neuropathy patients, had a LP:DT ratio below 1.7, the ISCEV cut-off level. The group difference in the LP:DT ratio seems to be primarily contributed by the greater dark trough amplitudes in the optic neuropathy group.

The RPE forms a barrier between the retina and the systemic circulation, and it performs many vital functions to support the neural retina $[15,16]$. As the LP:DT ratio is a manifestation of the corneo-fundal potential generated by the RPE, the results of the present study indicate that significant abnormalities can occur in RPE in a majority of patients with bilateral, demyelinating optic neuropathy. However, it is found that both normal rods and rod photoreceptor-RPE interface are required for a normal EOG $[17,18]$. Therefore, abnormality in the EOG is not only diagnostic of abnormality of RPE function but also could be due to dysfunction in rod photoreceptor-RPE interaction as well. The mechanism for the light rise in EOG has been studied since the introduction of the concept of EOG [19]. The current understanding is that a substance is released from the rod outer segment to set off a rise in inositol triphosphate through an apical membrane receptor [20]. This in turn causes a subsequent rise in intracellular free calcium. Then calcium-activated chloride channel will be operated leading to depolarization of the basal membrane of the RPE resulting in initiation of light rise [20-22]. Though many mechanisms have been postulated to explain light rise, still there is no proper mechanism deduced to describe the mechanism of dark trough. Given the role of changes in basolateral chloride conductance regulating the light peak, it is possible to think that the dark trough is generated through a decrease in basolateral chloride conductance [23]. EOG abnormalities observed in our study could be due to a derangement in the chloride conductance which could have occurred as a result of acute episode of optic neuropathy. But the exact mechanism of this ionic abnormality cannot be ascertained.

However, based on the structural and functional abnormalities of optic neuropathy and the unique anatomical arrangement of RPE, alternative mechanisms can potentially contribute for EOG changes that we observed. First, Brudet-Wickel and van Lith reported evidence of partial, temporary disturbance of the choroidal circulation in anterior ischemic optic neuropathy that may cause for the abnormalities of light rise in EOG. Since the choroid is the principal vascular structure nourishing the outer retinal layers and the RPE, disturbance of choroidal circulation could have caused hypoxia of the retinal tissues [6]. This in turn can cause abnormalities in photoreceptors and RPE which is reflected in EOG as a reduction in LP:DT ratio in patients of our study.

Second, disc edema associated with optic neuropathy could lead to accumulation of fluid creating sub retinal space above the RPE [24, 25]. Such sub retinal space could interfere with light reaching the photoreceptors and then alter the surface-recordings of RPE-generated EOG potentials. Third, some patients with optic neuropathy of our study show P50 component of PERG involvement which can be due to photoreceptor damage [26]. This damage in photoreceptor cell layer in turn can cause abnormalities in RPE which closely interact with the photoreceptors [27].

\section{Conclusions}

We conclude that RPE exhibits abnormal function as indexed by reduced LP:DT ratio primarily contributed by the increased dark trough amplitudes in EOG in the majority of patients with bilateral optic neuropathy. 


\section{Limitations}

MRI and optical coherence tomography (OCT) facilities were not available readily for every patient due to financial constraints. Also, further studies using a large cohort of patients would add more conclusive evidence.

\section{Supplementary information}

Supplementary information accompanies this paper at https://doi. org/10.1186/s13104-020-05131-0.

Additional file 1: Table S1. Median latencies and amplitudes of PRVEP between optic neuropathy group and the controls. Table S2. Median latencies and amplitudes of PERG between optic neuropathy group and the controls.

\section{Abbreviations}

DT: Dark trough; EMG: Electromyography; EOG: Electro-oculography; IQR: Inter quartile range; ISCEV: International society for clinical electrophysiology of vision; LogMAR: Logarithm of the minimal angle of resolution; LP: Light peak; MRI: Magnetic resonance imaging; OCT: Optical coherence tomography; PERG: Pattern electroretinography; PRVEP: Pattern reversal visual evoked potentials; RAPD: Relative afferent pupillary defect; RPE: Retinal pigment epithelium.

\section{Acknowledgements}

Authors wish to thank all the subjects in the study and consultant ophthalmologists who referred patients for the study.

\section{Authors' contributions}

PD designed and carried out the study, organized and interpreted data, did statistical analysis and drafted the manuscript. TD designed, did formal analysis, reviewed and edited the manuscript. MP designed, provided resources, did formal analysis, reviewed and edited the manuscript. SS designed, provided resources, did formal analysis, reviewed and edited the manuscript. MS designed, did formal analysis, reviewed and edited the manuscript. WW designed the study, did formal analysis, reviewed and edited the manuscript. All authors read and approved the final manuscript.

\section{Funding}

This research was funded by University of Peradeniya research Grant (URG/2016/44/M) only to purchase the Nicolet Viking Quest machine.

\section{Availability of data and materials}

The data sets used and/or analysed during the current study are available from the corresponding author on reasonable request.

\section{Ethics approval and consent to participate}

Ethical clearance (2016/EC/50) for the study was obtained from the Ethical Review Committee, Faculty of Medicine, University of Peradeniya, Sri Lanka. The study design and protocols complied with the code of ethics of the World Medical Association Declaration of Helsinki [10]. The procedures were explained and informed written consent obtained from all participants.

\section{Consent for publication}

Not applicable.

\section{Competing interests}

The authors declare that they have no competing interests.

\section{Author details}

${ }^{1}$ Department of Physiology, Faculty of Medicine, University of Peradeniya, Peradeniya 20400, Sri Lanka. ${ }^{2}$ Teaching Hospital, Peradeniya 20400, Sri Lanka. ${ }^{3}$ School of Psychology, The University of Newcastle, Callaghan, NSW 2308, Australia. ${ }^{4}$ Department of Medicine, Faculty of Medicine, University of Peradeniya, Peradeniya 20400, Sri Lanka. ${ }^{5}$ Eye Unit, National Hospital, Kandy 20000, Sri Lanka.
Received: 9 April 2020 Accepted: 6 June 2020

Published online: 12 June 2020

\section{References}

1. Behbehani R. Clinical approach to optic neuropathies. Clin Ophthalmol. 2007; 1(3):233-46

2. Naismith RT, Tutlam NT, Xu J, Shepherd JB, Klawiter EC, Song SK, et al. Optical coherence tomography is less sensitive than visual evoked potentials in optic neuritis. Neurology. 2009;73(1):46-52.

3. Arden GB, Barrada A, Kelsey JH. New clinical test of retinal function based upon the standing potential of the eye. $\mathrm{Br} J$ Ophthalmol. 1962;46(8):449-67.

4. Constable PA, Bach M, Frishman LJ, Jeffrey BG, Robson AG, International Society for Clinical Electrophysiology of V. ISCEV Standard for clinical electro-oculography (2017 update). Doc Ophthalmol. 2017;134(1):1-9.

5. Whatham AR, Nguyen V, Zhu Y, Hennessy M, Kalloniatis M. The value of clinical electrophysiology in the assessment of the eye and visual system in the era of advanced imaging. Clin Exp Optom. 2014;97(2):99-115.

6. Brudet-Wickel $\mathrm{CL}$, van Lith $\mathrm{GH}$. Electrophysiology in acute anterior ischaemic optic neuropathy. Ophthalmologica. 1984;188(2):111-7.

7. ONTT. The clinical profile of optic neuritis: experience of the optic neuritis treatment trial. JAMA Ophthalmol. 1991;109(12):1673-8.

8. Woung L-C, Chung H-C, Jou J-R, Wang K-C, Peng P-H. A comparison of optic neuritis in Asian and in Western Countries. Neuro-Ophthalmol. 2011;35(2):65-72.

9. de la Cruz J, Kupersmith MJ. Clinical profile of simultaneous bilateral optic neuritis in adults. Br J Ophthalmol. 2006:90(5):551-4.

10. Association WM. World Medical Association Declaration of Helsinki: ethical principles for medical research involving human subjects. JAMA 2013;310(20):2191-4.

11. Bach M, Brigell MG, Hawlina M, Holder GE, Johnson MA, McCulloch DL, et al. ISCEV standard for clinical pattern electroretinography (PERG): 2012 update. Doc Ophthalmol. 2013:126(1):1-7.

12. Odom JV, Bach M, Brigell M, Holder GE, McCulloch DL, Mizota A, et al. ISCEV standard for clinical visual evoked potentials: (2016 update). Doc Ophthalmol. 2016;133(1):1-9.

13. Turksever C, Orgul S, Todorova MG. Comparing short-duration electrooculograms with and without mydriasis in healthy subjects. Klin Monbl Augenheilkd. 2015;232(4):471-6.

14. Constable PA, Ngo DL, Quinn S, Thompson DA. A meta-analysis of clinical electro-oculography values. Doc Ophthalmol. 2017;135:219-32.

15. Lakkaraju A, Umapathy A, Tan LX, Daniele L, Philp NJ, Boesze-Battaglia K et al. The cell biology of the retinal pigment epithelium. Prog Retin Eye Res. 2020:100846.

16. Fuhrmann S, Zou C, Levine EM. Retinal pigment epithelium development, plasticity, and tissue homeostasis. Exp Eye Res. 2014;123:141-50.

17. Arden GB, Wolf JE. Differential effects of light and alcohol on the electrooculographic responses of patients with age-related macular disease. Invest Ophthalmol Vis Sci. 2003:44(7):3226-32.

18. Arden GB, Barrada A. Analysis of the electro-oculograms of a series of normal subjects: role of the lens in the development of the standing potential. Br J Ophthalmol. 1962;46(8):468-82.

19. Arden $\mathrm{GB}$, Kelsey JH. Some observations on the relationship between the standing potential of the human eye and the bleaching and regeneration of visual purple. J Physiol. 1962:161:205-26.

20. Constable PA. A perspective on the mechanism of the light-rise of the electrooculogram. Invest Ophthalmol Vis Sci. 2014;55(4):2669-73.

21. Arden GB, Constable PA. The electro-oculogram. Prog Retin Eye Res. 2006;25(2):207-48.

22. Gallemore RP, Griff ER, Steinberg RH. Evidence in support of a photoreceptoral origin for the "light-peak substance". Invest Ophthalmol Vis Sci. 1988;29(4):566-71.

23. Constable PA, Ngo D. The slow light and dark oscillation of the clinical electro-oculogram. Clin Exp Optom. 2018;101(6):786-92.

24. Hedges TR, Vuong LN, Gonzalez-Garcia AO, Mendoza-Santiesteban CE, Amaro-Quierza M. Subretinal fluid from anterior ischemic optic neuropathy demonstrated by optical coherence tomography. Arch Ophthalmol. 2008;126(6):812-5. 
25. Hoye VJ, Berrocal AM, Hedges TR, Amaro-Quireza M. Optical coherence tomography demonstrates subretinal macular edema from papilledema. Arch Ophthalmol. 2001;119(9):1287-90.

26. Holder GE. Electrophysiological assessment of optic nerve disease. Eye. 2004;18(11):1133-43.

27. Steinberg RH. Interactions between the retinal pigment epithelium and the neural retina. Doc Ophthalmol. 1985;60(4):327-46.

\section{Publisher's Note}

Springer Nature remains neutral with regard to jurisdictional claims in published maps and institutional affiliations.
Ready to submit your research? Choose BMC and benefit from:

- fast, convenient online submission

- thorough peer review by experienced researchers in your field

- rapid publication on acceptance

- support for research data, including large and complex data types

- gold Open Access which fosters wider collaboration and increased citations

- maximum visibility for your research: over 100M website views per year

At BMC, research is always in progress.

Learn more biomedcentral.com/submissions 